\title{
Historically and Currently Used Dechloranes in the Sediments of the Great Lakes
}

\author{
Ruiqiang Yang, ${ }^{+, \neq}$Hua Wei, ${ }^{\dagger}$ Jiehong Guo, $^{+}$Colin McLeod, ${ }^{+}$An Li, ${ }^{+, *}$ and Neil C. Sturchio ${ }^{\S}$ \\ ${ }^{\dagger}$ School of Public Health, University of Illinois at Chicago, Chicago, Illinois 60612, United States \\ ${ }^{\ddagger}$ State Key Laboratory of Environmental Chemistry and Ecotoxicology, Research Center for Eco-Environmental Sciences, \\ Chinese Academy of Sciences, Beijing 100085, China \\ ${ }^{\S}$ Department of Earth and Environmental Sciences, University of Illinois at Chicago, Chicago, Illinois, United States \\ Supporting Information
}

ABSTRACT: Dechlorane (mirex), Dechlorane Plus (DP), Dechlorane 602 (Dec602), Dechlorane 603 (Dec603), Dechlorane 604 (Dec604), and Chlordecone (Kepone) were analyzed in 16 sediment cores collected in 2007 from the Great Lakes of North America. Results show that Lake Ontario sediments have accumulated mirex, DP, Dec602 and Dec604 in amounts 1 to 2 orders of magnitude higher than other Great Lakes. The chemical inventory decreases log-linearly with increasing latitude (N) and longitude (W) of the sampling locations, but Lake Ontario sites are outliers in the regression against latitude. The regression analyses suggest differences among the analytes with regard to source impact and long-range transport behavior. Temporal trends of input differ among lakes. Most sites in Lake Superior are still receiving increasing fluxes of DP and Dec602, while these have been declining in Lake Ontario from the peak around 1990. The relative abundance of the two DP isomers, represented by $f_{\text {syn }}$ increases with increasing distance from the potential dis-

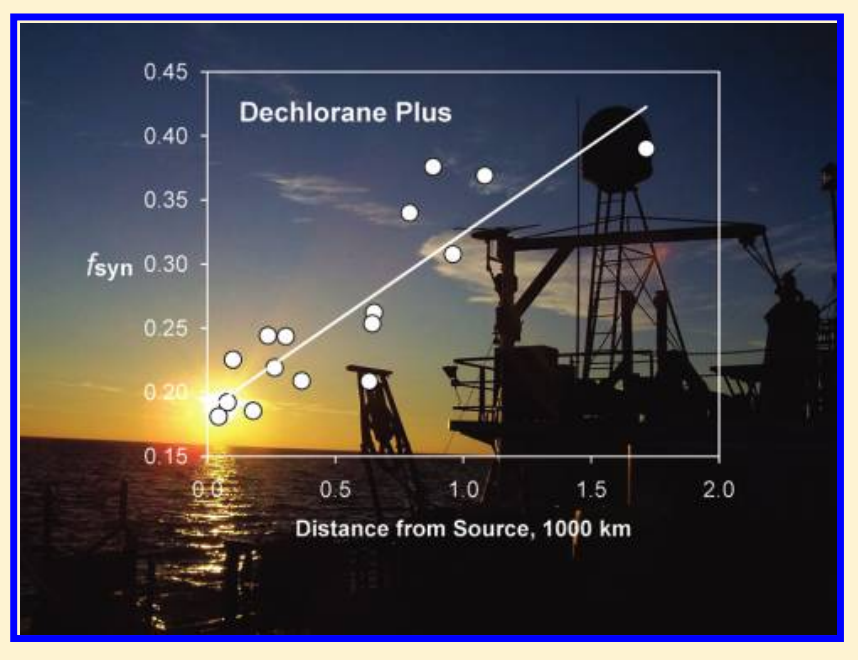
charge source in Niagara Falls, NY, suggesting the anti-DP isomer is more vulnerable to degradation during long-range atmospheric transport. Kepone was not detected in the sediments of Lakes Ontario, Erie, and Michigan.

\section{INTRODUCTION}

For North America, 610 organic substances are prioritized for environmental monitoring, about $70 \%$ of which are halogenated organic compounds. ${ }^{1}$ These include polychlorinated biphenyls (PCBs), polybrominated diphenyl ethers (PBDEs) and many others which are of emerging concerns. Most emerging chemical pollutants are not regularly monitored, even for those with high production volumes. This work investigates seven Dechlorane related compounds, all highly chlorinated, in the sediment of the Great Lakes. Brief introductions of the target compounds are given below. Their chemical structures are provided in Table S1 of the SI.

Dechlorane was used as an additive flame retardant in plastics, paints, and electrical goods from 1959 to $1972 .^{2}$ Although the compound is more commonly known as the pesticide mirex, the majority (74\%) of its total production before 1977 by the major manufacturer Hooker Chemicals and Plastics Corp. was used as flame retardant. ${ }^{3}$ The use of technical Dechlorane and mirex was terminated in the U.S. in 1978. Mirex is one of the "Dirty Dozen" under the Stockholm Convention on Persistent Organic Pollutants, and research has revealed its globally ubiquitous presence. However, it is not clear how much of the pollution was actually due to its use as a flame retardant relative to its use as a pesticide.

Dechlorane Plus (DP) is another highly chlorinated nonplasticizing flame retardant, which largely replaced Dechlorane with high annual production quantities by OxyChem at its Niagara Falls, New York, facility to this day. ${ }^{4}$ From the application perspective, DP is advantageous over bromine-based flame retardants due to its thermal and photochemical stabilities, lower density, and lower cost. ${ }^{5} \mathrm{DP}$ is added to industrial polymers used as coatings for commercial electrical wires and cables, in connectors used in computers, and in plastic roofing material for commercial buildings. ${ }^{5}$ Since the first detection of DP in the environment, ${ }^{6}$ its ubiquitous presence has been confirmed with reports from all major continents except Africa, and in various environmental media and human samples.

Received: March 30, 2011

Accepted: May 16, 2011

Revised: $\quad$ May 10, 2011

Published: May 26, 2011 


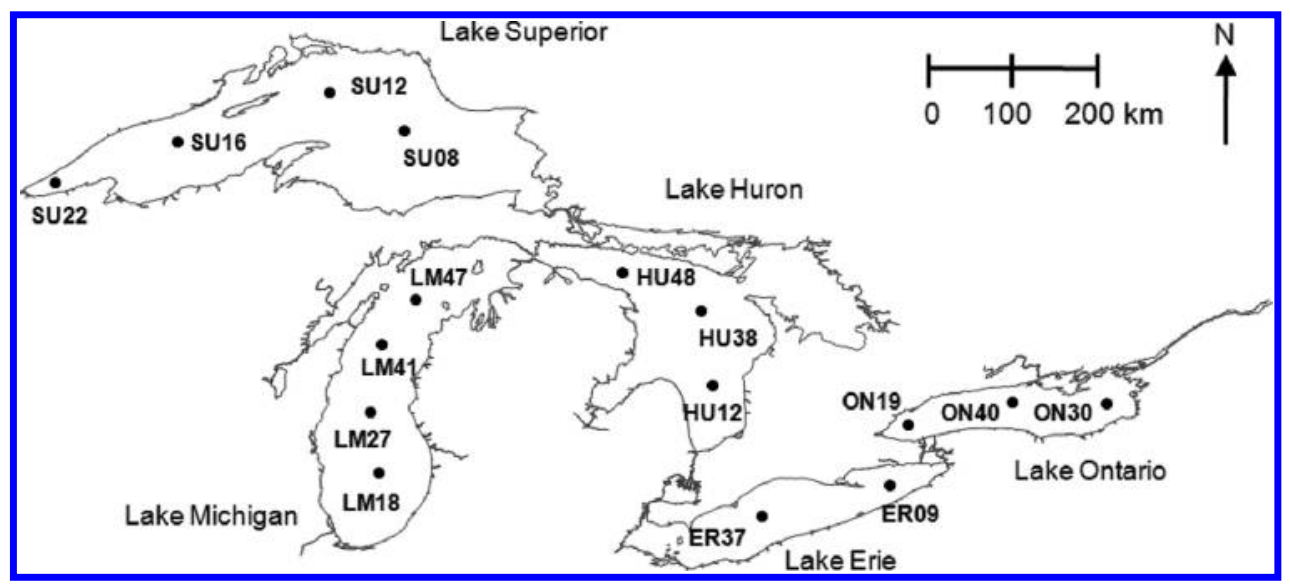

Figure 1. Sampling locations.

Dechloranes 602 (Dec602), 603 (Dec603), and 604 (Dec604) were patented as fire retardant chemicals in the 1970s. Dec602 and Dec604 are probably still being produced, ${ }^{7}$ although no confirmative information is found. It is suspected that Dec603 may be an impurity in technical grade pesticide aldrin, based on their chemical structures and the analysis of the pesticide. ${ }^{8}$ The presence of these three Dechloranes in the environment was not discovered until recently. ${ }^{7,8}$

Chlordecone, with trade names Kepone, merex, and others, is a ketone analog of Dechlorane. It was introduced in 1951 as an insecticide, and was also present as a contaminant $(2.6 \mathrm{ppm})$ in technical grade mirex. ${ }^{9}$ In the U.S., Kepone was produced by Allied Chemical Corporation in Hopewell, Virginia, with a large proportion being exported. Kepone was also manufactured by Hooker Chemicals and Plastics Corp. at Niagara Falls, NY. ${ }^{3}$ The manufacturing was terminated in 1976 when production workers developed serious neurological disorders, ${ }^{10}$ and the James River and Chesapeake Bay were found to be severely contaminated. Kepone was reported to form from the degradation of mirex in aquatic environment. ${ }^{11}$ In 2009, Kepone was added to the list of the Stockholm Convention as one of the nine "new" persistent organic pollutants. ${ }^{12}$

In this research, we investigated the above polychlorinated organics in the sediments of all five Laurentian Great Lakes in North America. Similar to those for our previous projects on PBDEs and PCBs, ${ }^{13-18}$ the objectives of this project are to reveal the spatial distribution pattern of sediment contamination on a regional scale, retrieve the history of pollution naturally recorded by the sediment in all the Great Lakes, examine the factors related to the accumulation, and provide information needed to understand their sources, and their transport and fate in the environment.

\section{EXPERIMENTAL SECTION}

Sampling. A sampling trip took place in August 2007 onboard the U.S. Environmental Protection Agency (EPA) Research Vessel (R/V) Lake Guardian. A total of 16 locations were sampled, and most of them were far away from the shorelines (Figure 1 and Table S2 of the SI). The sediment cores were collected using a $0.084 \mathrm{~m}^{3}$ box corer. The boxed bulk sediment was then cored on the deck with four polycarbonate tubes (7.0 cm I.D. AIN Plastics, Inc., Bensenville, IL). The cores were frozen onboard, and transported to the laboratory, where they were sectioned in a laboratory freezer room using a Torrey electric saw (model ST-295 PE). For all cores except the one collected at HU-48, sectioning was conducted at $0.5 \mathrm{~cm}$ intervals from the surface to $2 \mathrm{~cm}$ and then $1 \mathrm{~cm}$ intervals down to depth $10 \mathrm{~cm}$, and finally at $5 \mathrm{~cm}$ intervals to the bottom of the core. For HU-48, the cores were sectioned at $0.5 \mathrm{~cm}$ intervals from the surface to $1 \mathrm{~cm}$, then $1 \mathrm{~cm}$ intervals down to $10 \mathrm{~cm}$, and $5 \mathrm{~cm}$ intervals for the rest of the core. The segments at the same depth of cores collected at each location were combined. A total of 223 samples were obtained, and they were stored frozen until analysis.

Sediment Characterization. The samples were analyzed for water content, from which the porosity and the dry bulk density were calculated with a constant particle density of $2.54 \mathrm{~g} / \mathrm{cm}^{3}$, which was both the average and the median of previously measured value for sediments in all the Great Lakes. ${ }^{18}$ Organic matter (OM) content was measured gravimetrically by loss on ignition (LOI) at $550^{\circ} \mathrm{C}$.

For 14 of the 16 sampling sites, the mass sedimentation rate (MSR) and focusing factor (FF) were previously determined from radioactive isotope $\mathrm{Pb}-210$ measurement. ${ }^{14-16}$ They are summarized in SI Table S2. The MSR and FF for LM-27 were from Hermannson et al. ${ }^{19}$ for central Lake Michigan station CLM-M. For ON-19, ${ }^{210} \mathrm{~Pb}$ and ${ }^{137} \mathrm{Cs}$ activities were measured in this work using gamma spectrometry with a Canberra model GR3020 reverse-electrode intrinsic Ge detector system (34\% efficiency) interfaced with a DSA-2000 digital spectrum analyzer. Dry sediment samples $(7.6-26 \mathrm{~g})$ were weighed into thin aluminum counting cans and sealed. Gamma activities were measured for ${ }^{210} \mathrm{~Pb}$ at $46.5 \mathrm{keV}$ and for ${ }^{137} \mathrm{Cs}$ at $661.6 \mathrm{keV}$. Detector efficiency was calibrated in the same geometry using certified standards DL-1a (CANMET, U-Th ore) and SRM4357 (NIST, ocean sediment). Both the constant initial concentration (CIC) and the constant rate of sedimentation (CRS) models were applied to the ${ }^{210} \mathrm{~Pb}$ data, as described previously. ${ }^{15}$

Chemical Analysis. Dec602 (95\%), Dec603 (98\%), and Dec604 (98\%) were purchased from Toronto Research Chemical Inc. (Toronto, ON, Canada). Standards of syn-DP and antiDP were purchased from Wellington laboratories Inc. (Guelph, ON, Canada). Mirex and the surrogate ${ }^{13} \mathrm{C}$-labeled PCB209 (PCB209L) and internal standard ${ }^{13}$ C-labled PCB205 (PCB205L) were purchased from Cambridge Isotope Laboratories Inc. (Andover, MA). Kepone (>99\% purity) and surrogate 2,4,4'-tribromodiphenyl ether (BDE30) was purchased from 
AccuStandard (New Haven, CT). All the solvents used were residue-analytical grade and purchased from Fisher Scientific (Pittsburgh, PA). Silica gel (100-200 mesh, Davisil grade 644) and anhydrous sodium sulfate $\left(\mathrm{Na}_{2} \mathrm{SO}_{4}\right)$ were purchased from Fisher. The $\mathrm{Na}_{2} \mathrm{SO}_{4}$ was cleaned at $550{ }^{\circ} \mathrm{C}$ for $5 \mathrm{~h}$ and silica gel was activated at $160^{\circ} \mathrm{C}$ for $14 \mathrm{~h}$.

The frozen samples were thawed and air-dried in the laboratory. Then, 2 to $10 \mathrm{~g}$ of the dried sample was accurately weighed, and mixed with about $30 \mathrm{~g}$ activated $\mathrm{Na}_{2} \mathrm{SO}_{4}$. The mixture was spiked with two surrogates, BDE30 and PCB209L, and Soxhlet extracted using $160 \mathrm{~mL}$ hexane-DCM (1:1, v/v) for $24 \mathrm{~h}$. Granular copper was added to remove elemental sulfur. The extract was then concentrated to about $1 \mathrm{~mL}$ using a rotary evaporator.

The column for cleanup was made of Pyrex glass, and was $300 \mathrm{~mm}$ long with $10 \mathrm{~mm}$ i.d. It was fitted with Pyrex glass wool and a PTFE stopcock at the bottom, and prefilled with dichloromethane. The column was then packed from bottom to top $1 \mathrm{~g}$ silica gel, 4 g acidic silica gel (40\%, w/w, concentrated sulfur acid), $1 \mathrm{~g}$ activated silica gel, and $2 \mathrm{~g}$ granular anhydrous $\mathrm{Na}_{2} \mathrm{SO}_{4}$. After pre-eluting the column with $50 \mathrm{~mL}$ of hexane, the extract was added and eluted using $70 \mathrm{~mL}$ of $5: 1(\mathrm{v} / \mathrm{v})$ hexane: dichloromethane mixture. The eluate was concentrated by rotary evaporation and finally reduced to $1 \mathrm{~mL}$ by a gentle nitrogen stream. Internal standard (PCB205L) was added before instrumental analysis.

Analyses were performed using an Agilent 6890/5973 GC/ MS with an electron capture negative ionization (ECNI) source. For each run, a volume of $60 \mu \mathrm{L}(20 \mu \mathrm{L} \times 3)$ was introduced via a programmable temperature vaporization (PTV) injection port in solvent vent mode. The temperature program for the PTV inlet was from $40{ }^{\circ} \mathrm{C}$ (holding for $1.5 \mathrm{~min}$ ) to 300 at $600{ }^{\circ} \mathrm{C} \mathrm{min}{ }^{-1}$. The vent flow was $300 \mathrm{~mL} \mathrm{~min}{ }^{-1}$. The purge flow was $50 \mathrm{~mL}$ $\mathrm{min}^{-1}$ at the run time of $2.75 \mathrm{~min}$. An Rtx 1614 capillary column $(15 \mathrm{~m} \times 0.25 \mathrm{~mm}$ i.d. $\times 0.10 \mu \mathrm{m}$ film thickness $)$ was used for separation. Helium was used as carrier gas at constant flow of $1.2 \mathrm{~mL} \mathrm{~min}{ }^{-1}$. The initial oven temperature was $80^{\circ} \mathrm{C}$, which lasted for $3 \mathrm{~min}$, then increased to 140 at $10^{\circ} \mathrm{C} \mathrm{min}^{-1}$ and further to 300 at $5^{\circ} \mathrm{C} \min ^{-1}$. The final temperature was kept for $15 \mathrm{~min}$. The MS ion source, quadrupole and interface temperatures were 150, 106, and $280{ }^{\circ} \mathrm{C}$, respectively. Methane was used as moderating gas. The MS was operated in selected ion monitoring (SIM) mode with the primary/secondary ions being 340.8/613.6 for Dec602, 635.6/637.6 for Dec603, 79/81 for Dec604, 652/ 654 for both DP isomers, and 340.8/none for mirex. Quantification was performed by internal standard calibration, using the primary ion of each compound.

Quality Control. Procedural blanks were samples using $\mathrm{Na}_{2} \mathrm{SO}_{4}$ in place of sediment. One blank was analyzed for each core, using the same laboratory procedures as used for the sediment samples. The concentration levels in the procedural blanks were all below the method detection limit (MDL, see below) except for Dec603 which was found at 0.028 to $0.061 \mathrm{ng} \mathrm{g}^{-1}$ in 5 out of the 16 blanks. The average recoveries of the two surrogates, PCB209L and BDE30, were $83.4 \pm 12.5 \%(N=246)$ and $80.3 \pm 21.2 \%(N=$ $100)$, respectively. The concentrations reported in this paper were after subtraction of the procedural blank levels and corrections based on the surrogate PCB209L recovery. The analyte recoveries in spiked method blanks ranged from 92.2\% (Dec604) to $104.8 \%$ (Dec603). One sample in each core was analyzed in duplicate, and the average relative percentage differences (RPDs) of the duplicated analyses ranged from 18\% (for Dec604) to $39 \%$ (for mirex). Instrument detection limit (IDL) and method detection limit (MDL) are determined as $3 \times$ and $5 \times$ of the signal-to-noise ratio, respectively. The IDLs ranged from $0.018 \mathrm{ng} \mathrm{mL}^{-1}$ (for Dec603) to $0.124 \mathrm{ng} \mathrm{mL}^{-1}$ (for mirex). The MDLs were in the range of $0.003-0.015 \mathrm{ng} \mathrm{g}^{-1}$ (for Dec603) to $0.021-0.103 \mathrm{ng} \mathrm{g}^{-1}$ (for mirex) with the use of $2-10 \mathrm{~g}$ samples.

Estimation of Inventory and Flux. Inventory is the accumulation of the chemical mass over a unit area, and is location specific. Flux is the rate of accumulation which changes over sediment depth or deposition year, and should be corrected for sediment focusing. These were estimated using the equations:

$$
\begin{gathered}
\text { inventory }\left(\mathrm{ng} \mathrm{cm}^{-2}\right)=\sum C_{i} \rho_{\mathrm{b}} d_{i} \\
\operatorname{flux}_{\mathrm{i}}\left(\mathrm{ng} \mathrm{cm}^{-2} \mathrm{y}^{-1}\right)=C_{i} \times \mathrm{MSR} / \mathrm{FF}
\end{gathered}
$$

where $C_{i}$ is the concentration in sediment segment $i\left(\mathrm{ng} \mathrm{g}^{-1} \mathrm{dw}\right)$, $\rho_{\mathrm{b}}$ is the dry mass bulk density $\left(\mathrm{g} \mathrm{cm}^{-3}\right)$, and $d_{i}$ is the thickness of segment $i$. The MSR is in $\mathrm{g} \mathrm{cm}^{-2} \mathrm{y}^{-1}$, and the FF is dimensionless.

\section{RESULTS AND DISCUSSION}

The organic matter content of the sediment samples averaged $71 \pm 30 \mathrm{mg} \mathrm{g}^{-1}$ with a median of $74 \mathrm{mg} \mathrm{g}^{-1}$. Site LM-27, located on a sill in the nondepositional zone of central Lake Michigan, differs from all other sites in that its top $5 \mathrm{~cm}$ of sediment is made almost completely of dense clay with low water content and OM content of only about $0.5 \%$. For site $\mathrm{ON}-19,{ }^{210} \mathrm{~Pb}$ dating generated MSR of $0.0187 \mathrm{~g} \mathrm{~cm}^{-2} \mathrm{y}^{-1}$ and a focusing factor of 1.11 , which are the averages from the CRS and CIC models (SI Figure S1).

The surface and the maximum concentrations for all sediment cores are compared with the literature data in Table S3 of the SI. Comparisons among locations are presented in SI Figures S2-S4 for the surface concentrations, inventory, and the recent flux of input, respectively. Figure 2 presents the regressions of the natural logarithm inventories against the latitude and longitude of the sampling locations; and additional statistics of regressions are summarized in SI Table S4. The chronological profiles of the fluxes are illustrated in Figure 3 for selected locations.

Dechlorane (Mirex). Mirex was detected at all sites, with a $96 \%$ detection rate for all samples dated 1950 or later. The concentrations ranged from 0.002 to $14 \mathrm{ng} \mathrm{g}^{-1} \mathrm{dw}$ in the surface $(0-0.5 \mathrm{~cm})$ sediment across the Great Lakes, which is in fair comparison with the range of $0.001-10 \mathrm{ng} \mathrm{g}^{-1}$ reported by Shen et al. ${ }^{7}$ for the top $0-3 \mathrm{~cm}$ at 23 locations (SI Table S3).

South-to-north and east-to-west log-linear decreasing gradients have been reported for PCBs and PBDEs in the sediments of the Great Lakes. ${ }^{13,17}$ As shown in Figure 2, the inventory of mirex in sediment is a strong function of the latitude and longitude of the sampling locations. The surface concentration and flux are also dependent on the latitude and longitude but with slightly weaker statistics (SI Table S4). The concentration of mirex in fish liver in Canadian lakes was also found to decline with increasing latitude ranging from about $43^{\circ}$ to $62^{\circ}$ North. $^{20}$

Lake Ontario sites are outliers in the regression against latitude. Apparently, the sediments there have accumulated much more mirex than the regression equation describes. Based on the historical records of discharge and investigations including this work, $>90 \%$ of the total mirex accumulation in the Great Lakes occurred in Lake Ontario. Historical monitoring data clearly pointed to the local point discharges as dominant mirex 

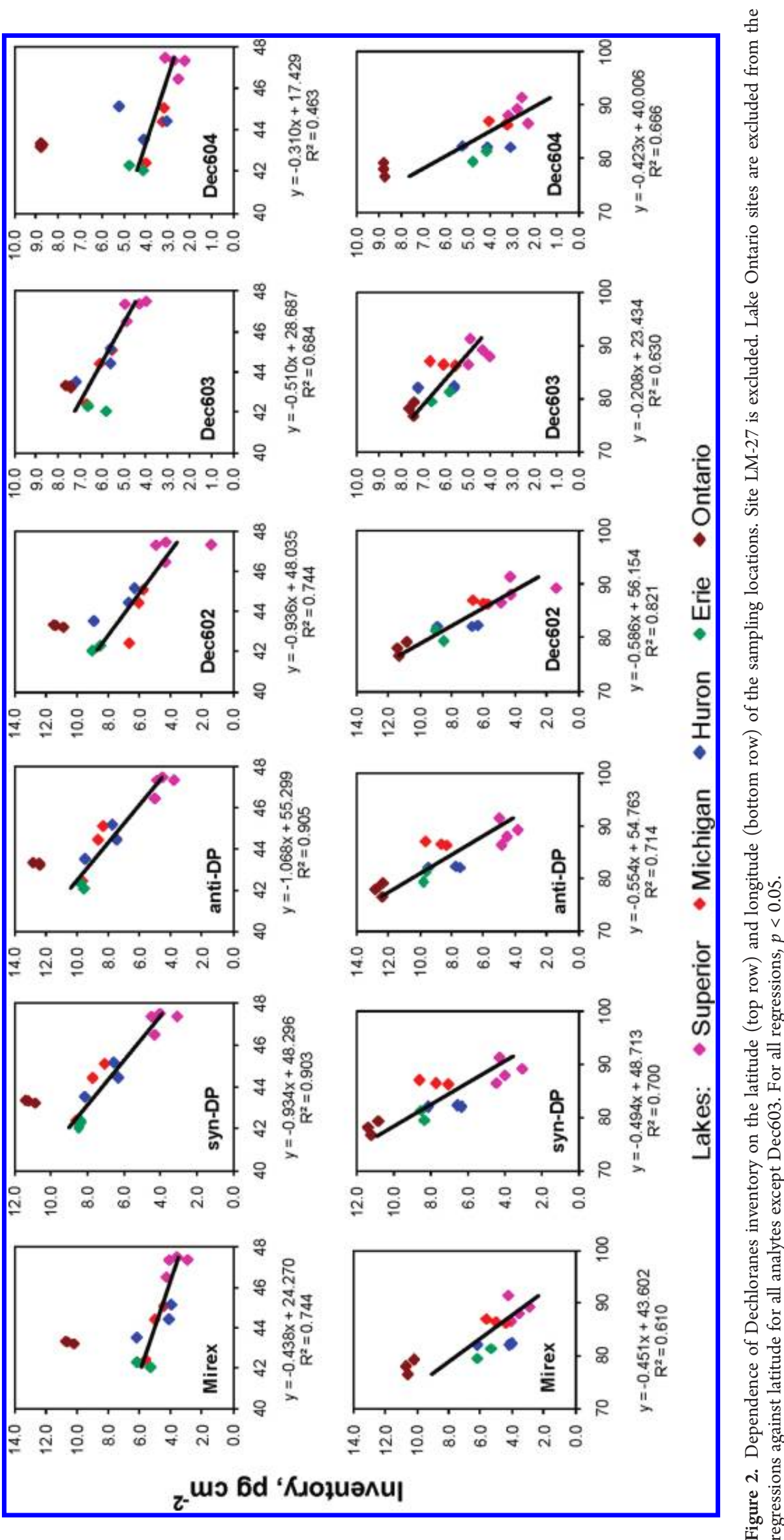


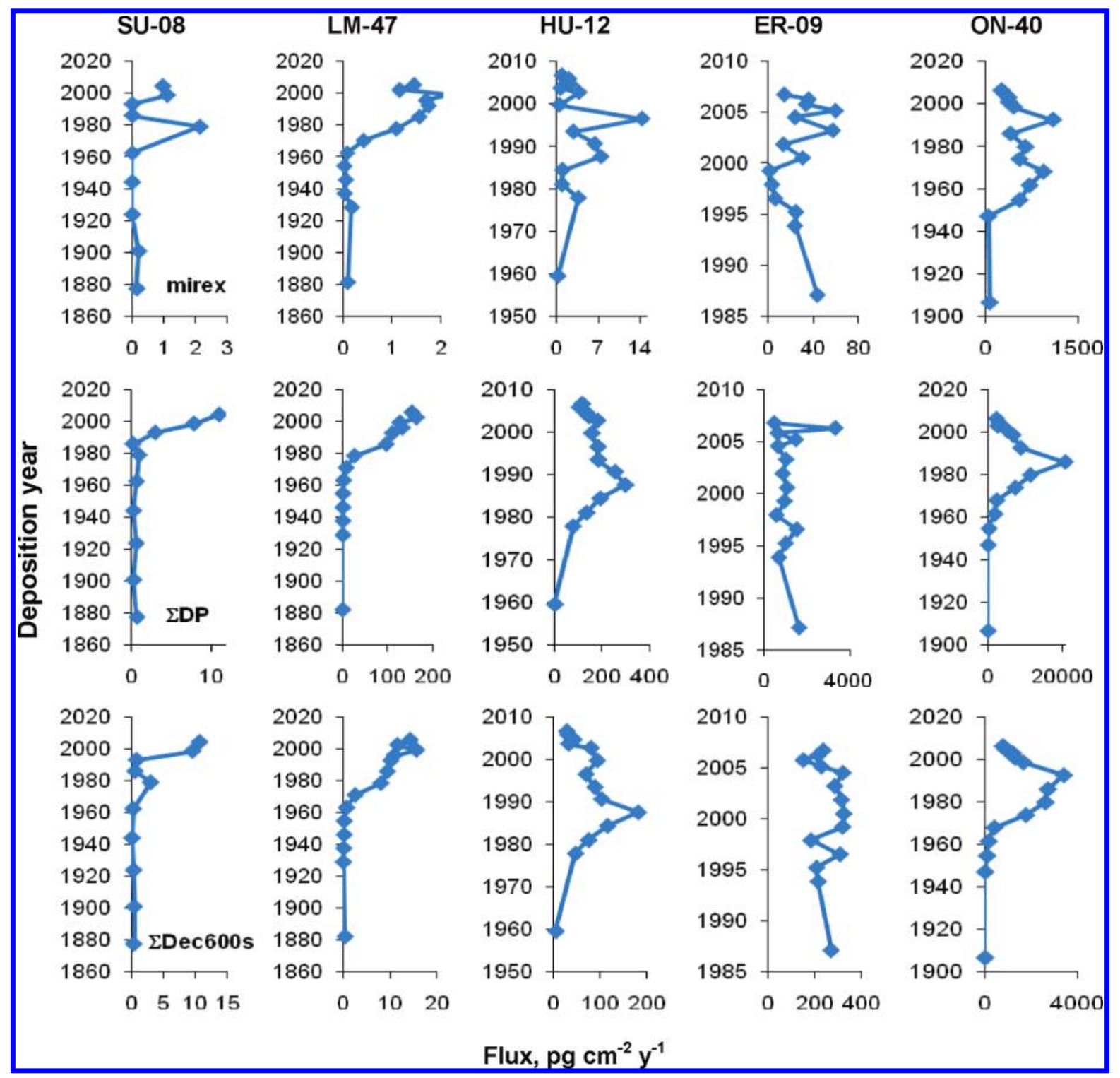

Figure 3. Flux of dechloranes to the sediments at selected locations in the Great Lakes.

input sources to the lake, including the Niagara River in the west basin and Oswego River in the east. ${ }^{21-23}$

The time trend recorded in the sediments, as illustrated in Figure 3, reveals that the decrease in concentration over time was gradual, suggesting that the environmental release of mirex had extended long after it was banned in 1978. It may also suggest the broadening of the peak has occurred due to gradient-induced upward and downward diffusion through the sediment column. This assumption is supported by comparisons of the maximum fluxes found in this work and reported in the literature. The peak fluxes found at ON-19, ON-30, and ON-40 are 0.7, 0.9, and $1.1 \mathrm{ng} \mathrm{cm}{ }^{-2} \mathrm{y}^{-1}$, which are comparable with those of the early 1990 s at about the same locations, ${ }^{24}$ but significantly lower than the range of $3-5.4 \mathrm{ng} \mathrm{cm}^{-2} \mathrm{y}^{-1}$ in 1981 near ON-30. ${ }^{22}$ In addition, there appears to be a 3 -years shift from the peak time of 1965-1967 reported in the late $1980 \mathrm{~s}^{22}$ to the peak time of 1968-1970 found in this work at locations ON-40 and ON-30.

Dechlorane Plus. DP was detected in all surface sediment segments and all $(N=146)$ but one of the segments dated after
1950. The site specific maximum concentration ranged from $0.3 \mathrm{ng} \mathrm{g}^{-1} \mathrm{dw}$ (SU-22) to $730 \mathrm{ng} \mathrm{g}^{-1} \mathrm{dw}$ (ON-19). Across the entire region, sediment contamination by DP is consistently higher than by all other analytes targeted in this work.

The inventories of DP at the three sites in Lake Ontario are 280, 310, and $450 \mathrm{ng} \mathrm{cm}{ }^{-2}$ at ON-19, ON-30, and ON-40, respectively; which are about $1-2$ orders of magnitude higher than those in other lakes (SI Figure S3). The strong dependences of the DP inventory on the latitude and longitude are similar to those for mirex (Figure 2). Hoh et al. ${ }^{6}$ suspected that the high concentration of DP in Lake Ontario is related to the point sources in Niagara Falls, NY, which is supported by the results of this work. With regard to the time trend, the DP input to sediment appeared to begin in the 1970s (Figure 3), in agreement with the finding of Shen et al. ${ }^{7}$ The recent fluxes are still $2-4 \mathrm{ng} \mathrm{cm}^{-2} \mathrm{y}^{-1}$ at the Lake Ontario sites, although they have declined from the peak of $14-20 \mathrm{ng} \mathrm{cm}^{-2} \mathrm{y}^{-1}$ in the $1990 \mathrm{~s}$ (Figure 3). As DP is still being produced at present, the decline of input to Lake Ontario may reflect the decrease in production 


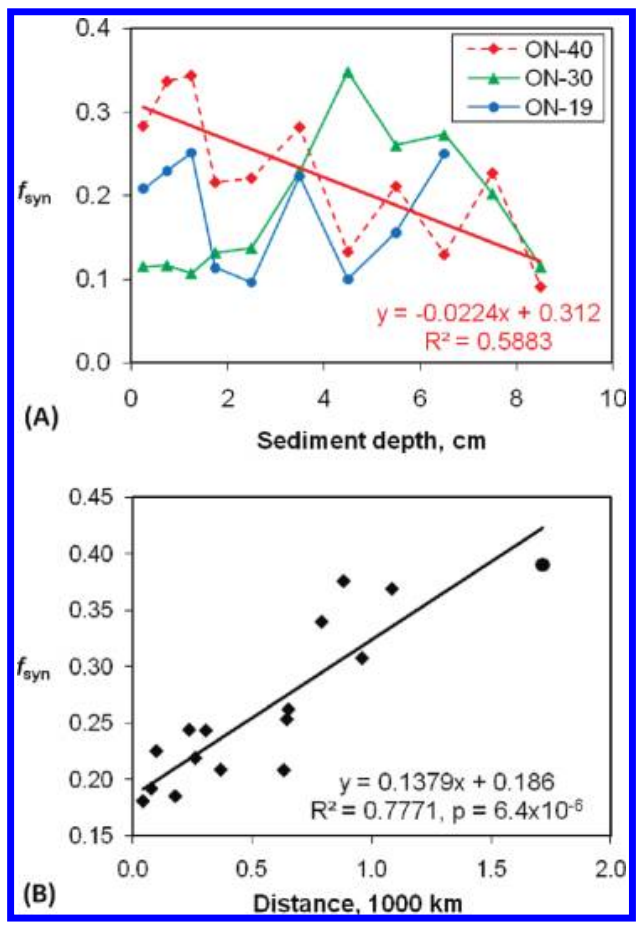

Figure 4. DP isomer profiles. (A) Isomer fraction of syn-DP, $f_{\text {syn }}$, versus sediment depth in Lake Ontario. The regression line is for site ON-40. (B) Site average $f_{\text {syn }}$ values versus the distance between the sampling locations and the DP manufacturing plant located in Niagara Falls, NY. The filled circle is the datum for Lake Winnipeg. ${ }^{26}$

volume or an improvement in controlling the discharge. In Lake Superior, DP input still increases at all sites except SU-22. At other remote locations including LM-47, HU-38, and HU-48, the recent fluxes showed a sign of decline only at the top segment of the cores.

DP has syn- and anti- stereoisomers. The variation in the fractional abundance of syn-DP, $f_{\text {syn }}$, has been used to explore the difference in environmental persistence between the two isomers. In this study, the $f_{\text {syn }}$ in all sediment samples dated after $1950(N=129)$ was in the range of $0.08-0.72$ with a mean \pm standard deviation of $0.24 \pm 0.09$ and a median of 0.23 . These are in good agreement with those reported from other freshwater sediment studies. ${ }^{6,25-27}$ It was suggested that the syn isomer could be more vulnerable to natural degradation, since a few reported $f_{\text {syn }}$ values for DP in the sediment were lower than in the technical DP mixture. ${ }^{6,27}$ However, the $f_{\text {syn }}$ values for technical DP mixture varied from 0.20 to 0.41 , as reported by different researchers. ${ }^{7}$ This inconsistency suggests caution when investigating stereoselective degradation of DP based on direct comparison between environmental and technical $f_{\text {syn }}$ values. Figure 4A demonstrates the lack of identifiable trend in $f_{\text {syn }}$ value with sediment depth in the three Lake Ontario cores. At ON-40, the $f_{\text {syn }}$ value shows a waving downward trend, similar to that previously reported. ${ }^{28}$ However, such trend was not observed at the other cores analyzed in this work (Figure 4A). Shen et al. ${ }^{7}$ also found no trend of the $f_{\text {syn }}$ value with sediment depth at another Ontario site. Overall, it appears that the relative abundance of the two DP isomers in technical products may not be constant over time and may vary among different manufacturers.

To better understand the variation of $f_{\text {syn }}$, we compared this ratio among sampling locations. Both the average and median $f_{\text {syn }}$ decreases in the order Superior $>$ Michigan $>$ Huron $>$ Erie $>$ Ontario. Highly statistically significant dependences of the core average $f_{\text {syn }}$ on both the latitude and longitude of the sampling locations were found. An even stronger correlation was found between the core average $f_{\text {syn }}$ and the distance between the sampling location and the DP manufacturing plant in Niagara Falls, NY (Figure 4B). Tomy et al. ${ }^{26}$ reported sediment $f_{\text {syn }}=$ 0.39 in the remote Lake Winnipeg (included in Figure 4B), in contrast to $f_{\text {syn }}=0.24$ in Lake Ontario. Sverko et al. reported higher $f_{\text {syn }}$ in Lake Erie than in Lake Ontario, using mostly surficial sediment samples. ${ }^{29}$ The marine sediment along the coast of northern China was found to have a $f_{\text {syn }}$ of $0.44 .^{30}$ The results of this work suggest that depletion of anti-DP relative to syn-DP during the long-range transport has occurred. Given that the transport of DP from its source region to remote areas is most likely via the atmosphere, the selective degradation of DP could occur photochemically in the air. We noticed, however, that no obvious trend was observed for the DP isomer ratio measured in tree barks with increasing distance from the source. $^{31}$ Future research on the relative stability of the DP isomers is warranted.

Dec600s. Dechloranes 602, 603, and 604 were only recently found in the environment, ${ }^{7}$ and this work is one of only a few studies for the Great Lakes. ${ }^{7,8}$ Among samples dated 1950 or later, the detection rates for Dec602, Dec603, and Dec604 were $94 \%, 100 \%$, and $86 \%$, respectively. Dec602 and Dec603 were detected in all surficial sediments. The concentrations of these three Dechloranes are much lower than those of mirex and DP, and in a general order of Dec602 > Dec603 > Dec604. The inventory of $\sum$ Dec600s (sum of Dec602, Dec603, and Dec604) was in the range of $59-100 \mathrm{ng} \mathrm{cm}^{-2}$ in Lake Ontario, 5.6$8.4 \mathrm{ng} \mathrm{cm}^{-2}$ in Lake Erie, $1.0-8.9 \mathrm{ng} \mathrm{cm}^{-2}$ in Lake Huron, $0.37-1.6 \mathrm{ng} \mathrm{cm}^{-2}$ in Lake Michigan and $0.09-0.28 \mathrm{ng} \mathrm{cm}^{-2}$ in Lake Superior.

Similar to mirex and Dechlorane Plus, the inventories of Dec600s show strong log-linear decreasing trends with the increasing latitude and longitude of the sampling locations (Figure 2). Again, Lake Ontario sites are outliers in the regression against latitude for Dec602 and, more remarkably, for Dec604. The spatial distribution of Dec602 closely resembles that of DP, as evidenced from the similarity between the slopes of their respective regression equations shown in Figure 2. However, both Dec604 and Dec603 differ from DP and Dec602 in spatial distribution pattern. Among all Dechloranes analyzed in this work, Dec604 is the only one with bromines in its molecule and has the highest molecular weight. The average surface concentration of Dec604 in Lake Ontario sediments is 175 times higher than the average of all other sites, showing strong impact of the point source. In clear contrast, Dec603 exhibited relatively uniform distribution among lakes. With an exception of site ON-19, the sediment surface concentrations of Dec603 at all locations were within the range of $0.03-0.62 \mathrm{ng} \mathrm{g}^{-1} \mathrm{dw}$. This finding is in agreement with those of Shen et al., 7,8 who detected Dec603 in technical aldrin and suggested that Dec603 found in the Great Lakes region was associated with the historic pesticide use.

The last row of Figure 3 shows the chronology of $\sum$ Dec600s input flux. Differences in temporal trend among the three Dec600s are not apparent. It appears that their input to the Great Lakes sediment began during the 1970s at all sites except the three open water locations in Lake Superior (SU-08, SU-12, and SU-16) where the commencement of the input was delayed to around 1980 and has been increasing since then. The peak 
time in most other locations was mostly around 1990, and there is a clear decline toward recent years in Lake Ontario as well as site HU-12 in Lake Huron. Temporal trends for Dec600s were previously reported for only one site near ON-40 in Lake Ontario, and they match well with the findings of this work.

Chlordecone (Kepone). Kepone was screened by reanalyzing the extracts of the samples collected from Lakes Ontario, Erie, and Michigan using the GC/MS with electron impact (EI) ion source. Kepone was not detected in any of these samples at instrument detection limit of $0.072 \mathrm{ng} \mathrm{mL}^{-1}$ which corresponds to $7.2-36 \mathrm{pg} \mathrm{g}^{-1} \mathrm{dw}$ when $2-10 \mathrm{~g}$ sediment was extracted. This was not unexpected, because (1) the amount of Kepone produced by the chemical plant near Niagara Falls, NY is likely to be minimal, although no production quantity data were found; (2) before 1975, only a small quantity of Kepone produced in the U.S. was used domestically while the majority was exported; (3) mirex may not degrade to Kepone easily through biological mechanisms in the environments or even under laboratory conditions, $^{32-34}$ and (4) the water solubility of Kepone is approximately 2000 times greater than that of mirex, ${ }^{34}$ and it is also more reactive and volatile than mirex, ${ }^{35}$ reducing the likelihood for its detection in sediments, even though trace levels of Kepone were reported in Lake Ontario Coho salmon in the 1970s. ${ }^{3}$ Based on these reasons, we conclude that Kepone contamination of the Great Lakes sediments is insignificant.

Implications to Long Range Transport. With the exclusion of Lake Ontario sites, the slopes of the regressions against latitude (Figure 2, top row) are about -1 for DP and Dec602. This translates into an exponential decline in accumulation to a fraction of 0.37 per degree latitude, or an empirical "half distance" (EHD) of about $77 \mathrm{~km}$ toward north. In comparison, the northward EHDs for mirex and Dec603 are much longer at approximately $180 \mathrm{~km}$. The regressions against longitude (Figure 2, lower row) as well as the distance from Niagara Falls, NY (SI Figure S5) also generated shorter EHDs (greater gradients) for DP and Dec602 than for mirex and Dec603. The northward EHDs are $125 \mathrm{~km}, 150 \mathrm{~km}$, and $110 \mathrm{~km}$ for PCBs, BDE47, and BDE209, respectively, similarly derived in our previous project but with Lake Ontario included. ${ }^{13,17}$ These differences may result from the stronger impact of the single, dominant point source for DP and Dec602 than for the others, as well as the chronological differences in the commencements of manufacturing and use among the chemicals. The finding of this work hints that DP could have a lower long-range transport potential than PCBs and PBDEs, at least within the time period of the past four decades. However, various urban and industrial input sources within the watersheds of individual lakes may contribute to the sediment accumulation, affecting the assessment of the long-range transport potential using sediment data alone. Without data in other media as well as the knowledge on various partitioning and degradation processes, it is difficult to further explain the differences in the long-range transport behavior among these chemicals or to apportion the contributions from air deposition and point discharge sources to the accumulation in the lakes.

Different from the cases of PCBs and PBDEs, ${ }^{13,17}$ Lake Ontario sites do not fall into the regressions against latitude for most Dechloranes. We believe that this difference is due to the lack of manufacturing facilities for PCBs and PBDEs in close proximity to the Great Lakes. Our findings, combined with those from other studies, ${ }^{7,8,28,29}$ suggest that industrial discharge or dumping, rather than diffuse sources which are often associated with population density, dominates the input of Dechloranes to Lake Ontario. The impact of such point sources on the contamination of Lake Ontario has been well documented. $3,7,8,21-24,28,29,36,37$ Such impact seems significant even at the open water locations that are far away from the suspected discharge point and the shorelines of the lake, due to the location of the source and the water circulation pattern of the lake. ${ }^{21,24,36,37}$ In other lakes, the major input is likely from urbanization related, nonpoint diffusive sources.

The results of Pearson's correlation analyses among the analytes are summarized in SI Table S5. In Lake Erie where sediment mixing is extensive thus a chronological trend cannot be established, the only two compounds that are statistically correlated are the two isomers of DP. This may imply that most correlations found in the other lakes are due only to the similar chronological patterns on a decade scale. As discussed above, the five Dechloranes were from different technical products, and may not share the same long-range transport potential.

Finally, as can be seen from comparing the statistics in SI Table S4, normalization based on the organic matter content of the sediments strengthens the correlations of surficial concentrations with latitude, longitude or the distance to the suspected source for all Dechloranes except Dec603. Given that Dec603 is associated with pesticides, ${ }^{8}$ its distribution in the Great Lakes may have been dominated by agriculture related discharges.

\section{ASSOCIATED CONTENT}

S Supporting Information. Additional Tables and Figures are available. This material is available free of charge via the Internet at http://pubs.acs.org.

\section{AUTHOR INFORMATION}

\section{Corresponding Author}

*Phone: +1 312-996-9597; fax: +1 312-413-9898; e-mail: anli@ uic.edu.

\section{ACKNOWLEDGMENT}

We thank the Captain and crew of the R/V Lake Guardian for their assistance in sampling. This research was funded by the Great Lakes National Program Office (GLNPO), U.S. Environmental Protection Agency.

\section{REFERENCES}

(1) Howard, P. H.; Muir, D. C. G. Identifying new persistent and bioaccumulative organics among chemicals in commerce. Environ. Sci. Technol. 2010, 44, 2277-2285.

(2) ASTDR. Mirex and Chlordecone. Toxfaqs; Agency for Toxic Substances and Disease Registry, September 1996.

(3) Kaiser, K. L. E. The rise and fall of mirex. Environ. Sci. Technol. 1978, 12, 520-528.

(4) U.S. EPA. High Production Volume Information System (HPVIS). http://www.epa.gov/hpvis/index.html (accessed December 2008).

(5) OxyChem. Dechlorane plus manual. http://www.oxy.com/our businesses/chemicals/documents/dechlorane_plus/dechlorane_plus.pdf (accessed October, 2006).

(6) Hoh, E.; Zhu; Hites, R. A. Dechlorane plus, a chlorinated flame retardant, in the Great Lakes. Environ. Sci. Technol. 2006, 40, 1184-1189.

(7) Shen, L.; Reiner, E. J.; MacPherson, K. A.; Kolic, T. M.; Sverko, E.; Helm, P. A.; Bhavsar, S. P.; Brindle, I. D.; Marvin, C. H. Identification 
and screening analysis of halogenated norbornene flame retardants in the Laurentian Great Lakes: Dechloranes 602, 603, and 604. Environ. Sci. Technol. 2010, 44, 760-766.

(8) Shen, L.; Reiner, E. J.; MacPherson, K. A.; Kolic, T. M.; Helm, P. A.; Richman, L. A.; Marvin, C. H.; Burniston, D. A.; Hill, B.; Brindle, I. D.; McCrindle, R.; Chittim, B. G. Dechloranes 602, 603, 604, dechlorane plus, and chlordene plus, a newly detected analogue, in tributary sediments of the Laurentian Great Lakes. Environ. Sci. Technol. 2011, 45, 693-699.

(9) Review of the Environmental Effects of Mirex and Kepone, EPA 600/1-78-013; Bell, M. A., Ewing, R. A., Lutz, G. A., Eds.; Prepared for the U.S. Environmental Protection Agency, by Battelle Columbus Laboratories: Washington, D.C. 1978.

(10) NIOSH. A Recommended Standard for Occupational Exposure to Kepone; Department of Health, Education and Welfare: Cincinnati, $\mathrm{OH}$, 1976.

(11) Carlson, D. A.; Konyha, K. D.; Wheeler, W. B.; Marshall, G. P.; Zaylskie, R. G. Mirex in environment - degradation to Kepone and related compounds. Science 1976, 194, 939-941.

(12) UNEP. www.chem.unep.ch/gpa_trial/17mirex.htm (accessed July, 2009).

(13) Li, A.; Rockne, K. J.; Sturchio, N.; Song, W.; Ford, J. C.; Buckley, D. R.; Mills, W. J. Polybrominated diphenyl ethers in the sediments of the Great Lakes. 4. Influencing factors, trends, and implications. Environ. Sci. Technol. 2006, 40, 7528-7534.

(14) Song, W.; Ford, J. C.; Li, A.; Sturchio, N. C.; Rockne, K. J.; Buckley, D. R.; Mills, W. J. Polybrominated diphenyl ethers in the sediments of the Great Lakes. 3. Lakes Ontario and Erie. Environ. Sci. Technol. 2005, 39, 5600-5605.

(15) Song, W.; Ford, J. C.; Li, A.; Mills, W. J.; Buckley, D. R.; Rockne, K. J. Polybrominated diphenyl ethers in the sediments of the Great Lakes. 1. Lake Superior. Environ. Sci. Technol. 2004, 38, 3286-3293.

(16) Song, W.; Li, A.; Ford, J. C.; Sturchio, N. C.; Rockne, K. J.; Buckley, D. R.; Mills, W. J. Polybrominated diphenyl ethers in the sediments of the Great Lakes. 2. Lakes Michigan and Huron. Environ. Sci. Technol. 2005, 39, 3474-3479.

(17) Li, A.; Rockne, K. J.; Sturchio, N.; Song, W. L.; Ford, J. C.; Wei, $\mathrm{H}$. PCBs in sediments of the Great Lakes - distribution and trends, homolog and chlorine patterns, and in situ degradation. Environ. Pollut. 2009, 157, 141-147.

(18) Li, A., Rockne, K. J., Sturchio, N. C., Mills, W. J., Song, W., Ford, J. C., Buckley, D. R. Chronology of pbde air deposition in the Great Lakes from sedimentary records. Final Report to USEPA. 2006; http:// tigger.Uic.Edu/ anli/final2.pdf (accessed March 1, 2011).

(19) Hermanson, M. H. C. E. R. Recent sedimentation in Lake Michigan. I. Great Lakes Res. 1991, 17, 33-50.

(20) Muir, D. C. G.; Ford, C. A.; Grift, N. P.; Metner, D. A.; Lockhart, W. L. Geographic-variation of chlorinated hydrocarbons in burbot (lota-lota) from remote lakes and rivers in canada. Arch. Environ. Contam. Toxicol. 1990, 19, 530-542.

(21) Durham, R. W.; Oliver, B. G. History of Lake-Ontario contamination from the Niagara River by sediment radiodating and chlorinated-hydrocarbon analysis. I. Great Lakes Res. 1983, 9, 160-168.

(22) Eisenreich, S. J.; Capel, P. D.; Robbins, J. A.; Bourbonniere, R. Accumulation and diagenesis of chlorinated hydrocarbons in lacustrine sediments. Environ. Sci. Technol. 1989, 23, 1116-1126.

(23) Holdrinet, M. V. H.; Frank, R.; Thomas, R. L.; Hetling, L. J. Mirex in the sediments of Lake Ontario. I. Great Lakes Res. 1978, 4, 69-74.

(24) Wong, C. S.; Sanders, G.; Engstrom, D. R.; Long, D. T.; Swackhamer, D. L.; Eisenreich, S. J. Accumulation, inventory, and diagenesis of chlorinated hydrocarbons in Lake Ontario sediments. Environ. Sci. Technol. 1995, 29, 2661-2672.

(25) Qi, H.; Liu, L.; Jia, H.; Li, Y.-F.; Ren, N.-Q.; You, H.; Shi, X.; Fan, L.; Ding, Y. Dechlorane plus in surficial water and sediment in a northeastern Chinese River. Environ. Sci. Technol. 2010, 44, 2305-2308.

(26) Tomy, G. T.; Pleskach, K.; Ismail, N.; Whittle, D. M.; Helm, P. A.; Sverko, E.; Zaruk, D.; Marvin, C. H. Isomers of dechlorane plus in
Lake Winnipeg and Lake Ontario food webs. Environ. Sci. Technol. 2007, 41, 2249-2254.

(27) Wu, J. P.; Zhang, Y.; Luo, X. J.; Wang, J.; Chen, S. J.; Guan, Y. T.; Mai, B. X. Isomer-specific bioaccumulation and trophic transfer of dechlorane plus in the freshwater food web from a highly contaminated site, South China. Environ. Sci. Technol. 2009, 44, 606-611.

(28) Qiu, X.; Marvin, C. H.; Hites, R. A. Dechlorane plus and other flame retardants in a sediment core from Lake Ontario. Environ. Sci. Technol. 2007, 41, 6014-6019.

(29) Sverko, E.; Tomy, G. T.; Marvin, C. H.; Zaruk, D.; Reiner, E.; Helm, P. A.; Hill, B.; McCarry, B. E. Dechlorane plus levels in sediment of the lower Great Lakes. Environ. Sci. Technol. 2008, 42, 361-366.

(30) Jia, H.; Sun, Y.; Liu, X.; Yang, M.; Wang, D.; Qi, H.; Shen, L.; Sverko, E.; Reiner, E. J.; Li, Y.-F. Concentration and bioaccumulation of dechlorane compounds in coastal environment of Northern China. Environ. Sci. Technol. 2011, 45, 2613-2618.

(31) Qiu, X.; Hites, R. A. Dechlorane Plus and other flame retardants in tree bark from the northeastern United States. Environ. Sci. Technol. 2008, 42, 31-36.

(32) Jones, A. S.; Hodges, C. S. Persistence of mirex and its effects on soil microorganisms. I. Agric. Food Chem. 1974, 22, 435-439.

(33) Mehendale, H. M.; Takanaka, A.; Desaiah, D.; Ho, I. K. Effect of preexposure to Kepone on hepatic mixed-function oxidases in the female rat. Toxicol. Appl. Pharmacol. 1978, 44, 171-180.

(34) Huckins, J. N.; Stalling, D. L.; Petty, J. D.; Buckler, D. R.; Johnson, B. T. Fate of Kepone and mirex in the aquatic environment. L. Agric. Food Chem. 1982, 30, 1020-1027.

(35) Kepone/Mirex/Hexachlorocyclopentadiene: An Environmental Assessment; Environmental Studies Board, Commission on Natural Resources, National Research Council, National Academy of Sciences: Washington, D.C, 1978.

(36) Marvin, C. H.; Charlton, M. N.; Stern, G. A.; Braekevelt, E.; Reiner, E. J.; Painter, S. Spatial and temporal trends in sediment contamination in Lake Ontario. L. Great Lakes Res. 2003, 29 (2), 317-331.

(37) Pickett, R. L.; Dossett., D. A. Mirex and the circulation of Lake Ontario. I. Phys. Oceanogr. 1979, 9, 441-445. 